\title{
EL CD-ROM LOS IBEROS Y SUS IMÁGENES. Una propuesta de análisis iconográfico de la cultura ibérica
}

POR

\author{
RICARDO OLMOS e ISABEL IZQUIERDO ${ }^{1}$ \\ Instituto de Historia, CSIC, Madrid ${ }^{2}$
}

PALABRAS CLAVE: Cultura ibérica. Iconografía ibérica. Cd-rom.

KEAY WORDS: Iberian culture. Iberian iconography. Cd-rom.

\section{RESUMEN}

Presentamos en este artículo el Cd-rom Los iberos y sus imágenes, de reciente aparición en el mercado, cuya realización ha sido posible gracias a una subvención de la DGICYT, mediante un proyecto PETRI que ha implicado la colaboración entre el CSIC y la empresa informática MICRONET S.A. La génesis y el planteamiento del proyecto parte de la exposición itinerante La sociedad ibérica a través de la imagen, que guía la estructura general del Cd-rom, adaptada al nuevo soporte. Este proyecto plantea una indagación compleja sobre la imagen en la cultura ibérica, en el contexto de las culturas del mediterráneo antiguo. Desde este punto de vista, se ha realizado un riquísimo catálogo con más de 1500 imágenes de la Protohistoria ibérica que cronológicamente van del Bronce Final hasta la romanización. Se ha pretendido elaborar una obra que suponga una herramienta de trabajo para cualquier especialista en la materia y, por otro lado, un rico y actualizado apoyo documental para cualquier usuario interesado en la cultura ibérica, la arqueología, la historia o las religiones y mitos del Mediterráneo antiguo.

\section{SUMMARY}

The paper presents the recently-published CR-ROM «The Iberians and their Images». The production of this CDROM has been possible thanks to the DGICYT (Madrid), through a PETRI project involving collaboration between CSIC and the computer company Micronet, SA. The project originated with the travelling exhibition La sociedad ibérica a través de la imagen, the layout of which inspired the structure of the CD-ROM, adapted to this new medium. The project provides complex research on images in the Iberian culture in the context of ancient Mediterranean cultures. From this point of view, it presents a very rich catalogue of over 1500 images of Iberian pre-history stretching from the late Bronze Age to the arrival of the Romans. The main objective has been to create a useful working tool for any specialis in the subject matter and to provide a rich and up-to-date document for any user interested in Iberian culture, of the archaeology, history and religions and myths of the ancient Mediterranean world.

\footnotetext{
1 Becaria postdoctoral por la Comunidad de Madrid.

2 E-mail: ceho134@ceh.csic.es (Ricardo Olmos) y cehi309@ceh.csic.es (Isabel Izquierdo).
}

\section{GÉNESIS Y PLANTEAMIENTO DEL PRO- YECTO $^{3}$}

La imagen constituye un campo ambiguo y difícil en los estudios de arqueología. Más aún si, como ocurre en el caso de la cultura ibérica, no contamos con documentos escritos que, expresa o indirectamente, la iluminen o apoyen. Algunos ven aún en la imagen un ámbito subjetivo de la investigación, que dejaría libertad a cualquier opinión improvisada y más o menos arbitraria. Otros optan por el recelo y se limitan a describir las imágenes de manera supuestamente aséptica, sin atreverse a emitir hipótesis alguna de interpretación. Pero ni la iconografía es el reino secreto y oscuro de la arqueología que se reserva a los iniciados, ni tampoco ese juego arbitrario donde todo vale. Al contrario, la iconografía constituye un sistema complejo de signos que se articulan en el espacio y en el tiempo de cada cultura. Como tal sistema la iconografía proyecta el pensamiento simbólico de una sociedad; forma parte de sus sucesivos imaginarios colectivos. Sus códigos figurativos conforman una práctica social, un uso compartido; se adaptan a unas pautas y tendencias - no tanto leyes- que en mayor o menor medida hoy resulta posible atisbar y establecer.

Del campo complejo y sugestivo de la iconografía ibérica nos venimos ocupando desde hace más de diez años un equipo de investigadores del departamento de Historia Antigua y Arqueología en el Instituto de Historia del Consejo Superior de Investigaciones Científicas (CSIC) de Madrid. Esta línea de trabajo ha ido perfilando su camino a través de sucesivos proyectos de investigación. Las discusiones y tanteos han formado parte del proceso de búsquedas; seminarios y cursos diversos han encauzado un diálogo cambiante con la imagen ibérica. Una de las preguntas principales de este largo debate ha sido la interpretación de estos sistemas de signos, tan enigmáticos en algunos casos, de los que apenas poseemos otras referencias salvo las propias imáge-

${ }^{3}$ Este trabajo forma parte del Proyecto de investigación, financiado por la DGICYT: "Introducción a un léxico de imagen prerromana en la Península ibérica” (PB 97-1124). 
nes. Algunas de nuestras búsquedas han visto la luz en artículos y en publicaciones monográficas. Apuntamos en la bibliografía algunos títulos.

En estas indagaciones se han hermanado las vertientes que llamaríamos más estrictamente científicas con las divulgativas. Ambas facetas forman parte del trabajo de investigación y constituyen un todo inseparable y dialéctico. Se enriquecen y proyectan mutuamente. No sabríamos discernir dónde comienzan una y otra faceta ni dónde establecer sus límites. La comunicación con otros ha iluminado cuestiones, imprecisas previamente, de nuestra tarea y ha enriquecido y perfilado nuestras búsquedas ${ }^{4}$. Y, sobre todo, ha ampliado el campo de las preguntas, extrayendo de la investigación minuciosa aquel fondo que resta en las ideas de realmente esencial y relevante. También ha servido como proceso de autoapredizaje y de crítica. En esta discusión que se ha pretendido abierta se han apuntado las principales cuestiones de un método interpretativo en relación con la imagen de la antigüedad algunos de cuyos resultados vamos a analizar a continuación.

Uno de los frutos principales de esta línea de investigación es el Cd-rom Los iberos y sus imágenes que aquí presentamos (Izquierdo, 1999; Izquierdo, Martínez Quirce, Mayoral y Morillo, 1998; Martínez Quirce y Mayoral, 1998; Olmos e Izquierdo, 2000a, b, c y en prensa). La realización del Cd-rom ha sido posible gracias a una subvención de la DGICYT, mediante un proyecto PETRI (proyecto de estímulo a la transferencia de resultados de la investigación). Según la filosofía de estos proyectos, se pretende que la empresa privada colabore en la difusión y comercialización de patentes y de resultados de investigación patrocinados y realizados desde organismos públicos. Esta colaboración no sólo ha llevado a la posibilidad de editar este Cd-rom, sino que nos ha abierto a una dialéctica entre lenguajes y métodos de trabajo completamente diversos: por un lado, la lógica del empresario (y la dinámica del mercado, la oferta y la demanda, que en última instancia regula y orienta el público al que se dirige el producto); y, por otro, el interés y la forma del discurso tan específicos a que estamos habituados, para bien y para mal, el gremio de los investigadores. Nuestro Cd-rom es en cierta medida reflejo de estas búsquedas y de estas diferencias. Veamos cuáles son algunas de ellas.

4 Victorino Mayoral (Universidad Complutense de Madrid) ha elaborado y diseñado la parte gráfica del Cd-Rom desde su experiencia complementaria de dibujante e investigador de la cultura ibérica. Su trabajo, que a veces reconstruye y evoca situaciones, actividades y paisajes, se ha integrado dentro del proceso creativo de nuestra investigación.
La estructura de no pocos Cd-rom de estas características tiende a un discurso más bien fragmentado, a base de pequeños textos que se apoyan en el mensaje más intuitivo y directo de la imagen. Las posibilidades de interrelación del medio permiten enlazar unos fragmentos con otros. Amplían el juego de las asociaciones por similitud o por contraste permitiendo, en definitiva, componer sobre ellas discursos y experiencias nuevas. Se abre así, pues, el campo de la selección fugaz y de las numerosas opciones - que pueden regirse por un propósito, o guiarse hacia lo inesperado por la aleatoria eventualidad de todo salto - lo que en principio podría enfrentarnos a ese discurso más cerrado y continuo al que nos han acostumbrado nuestros hábitos de investigación. En la práctica habitual de nuestra escritura solemos presentar un argumento básico que partiendo de una hipótesis inicial y, a través de análisis empíricos, nos conduce hacia una conclusión final. Hay una delineación previa de los objetivos, una meta definida en el horizonte para el lector y crítico. En el Cd-rom, en cambio, esta estructura cerrada puede resquebrajarse en fragmentos múltiples y en relaciones y nudos que derivan, especular o linealmente, el rumbo del pensamiento ${ }^{5}$. El destino del viaje, la meta permanece inconclusa y abierta.

No es éste el lugar de indagar en las posibilidades y límites a que en el ámbito del pensamiento nos abre esta nueva forma de buscar. Lo que desde este ángulo podría parecer una limitación es, desde la otra perspectiva, una fuente abundante de posibilidades. Pues también este nuevo medio permite otra forma de comunicación y un público diverso y diferente del restringido que acude a nuestros artículos y trabajos especializados. Nuestra práctica investigadora, generalmente financiada con fondos públicos, nos hace olvidar a veces la demanda social. En este Cd-rom se nos exigía una adaptación de nuestros intereses. El trabajo nos abría a otras búsquedas. Era preciso reordenar el lenguaje.

En un principio concebimos un Cd-rom que integrara aspectos lúdicos y científicos, comunicación y divulgación amplia junto con la parcela más estricta de la especialización. Pensamos también en un público amplio, al que se pudiera explicar de forma clara, sencilla y atractiva esta pequeña parce-

5 En este sentido existe el preligro de que el Cd-Rom potencie el tipo de lectura fragmentada y dispersa al que crecientemente tiende la investigación y al que nos aboca nuestra cultura pragmática de apariencias y de prisas. Pero este peligro surge realmente no tanto de los nuevos medios como de la estructura social en que se genera la práctica cotidiana de la ciencia. 
la de la historia que es el mundo ibérico. Ensayamos, incluso, textos de carácter diverso como un cuento de corte clásico, que escribió Paloma Cabrera (M.A.N.) e ilustró con acuarelas Victorino Mayoral (U.C.M.) desde su conocimiento y evocación reflexiva del paisaje ibérico ${ }^{6}$. La parcela del cuento nos abría facetas nuevas en la apropiación y evocación de la arqueología. Se plantearon también actividades varias, a través de un lenguaje multimedia. Se llegaron a diseñar reconstrucciones virtuales de yacimientos ibéricos, como la reconstrucción de un paisaje funerario monumental correspondiente a la necrópolis de Los Villares de Hoya Gonzalo (Albacete) o el recorrido de las murallas, calles y almacenes del poblado de La Quéjola (San Pedro, Albacete), cuyos guiones y diseño articuló Juan Blánquez (UAM). El mismo recorrido por la imagen ibérica se concibió como un paseo virtual por las Salas de un Museo imaginario a lo largo de las cuales nos aguardaban las imágenes ibéricas. Sin embargo, dada la envergadura de la vertiente científica, acordamos con la empresa dividir en dos productos diferentes este $\mathrm{Cd}$ originario que pretendía integrar los diversos niveles comunicativos. Lo que aquí presentamos es, por lo tanto, la vertiente más especializada y científica en forma de libro electrónico. Queda para un segundo momento el $\mathrm{Cd}$ didáctico. No obstante en este $\mathrm{Cd}$ final sobre imagen ibérica hemos mantenido un lenguaje claro e inteligible para el público culto no habituado a la jerga especializada de la iconografía y, en general, de la arqueología. La intención didáctica y abierta permanece y está latente en la concepción y guión de cada imagen y cada texto de este $\mathrm{Cd}$ que convencionalmente llamamos científico.

Nuestro objetivo final ha sido, pues, la publicación de un libro científico de alta divulgación, que abra caminos tanto al estudiante, fundamentalmente universitario, que quiera introducirse en la iconografía del mundo antiguo, como a un público culto interesado en cuestiones mítico-religiosas e históricas de nuestra protohistoria peninsular en el contexto del Mediterráneo. Pero también se dirige al especialista en imagen y arqueología ibérica.

Para cubrir estos objetivos hemos adoptado el lenguaje de programación del libro electrónico, que permite la combinación de textos e imágenes y que es sumamente flexible en la interrelación de los documentos, las búsquedas y la navegación, en general, entre los diferentes discursos.

${ }^{6}$ El lector puede acercarse a este cuento «Las tres pruebas» en el libro colectivo coordinado por A. Perea, 1999, $125-142$

\section{LA ESTRUCTURA DEL CD-ROM LOS IBE- ROS Y SUS IMÁGENES}

El Cd-Rom supone una indagación compleja sobre la imagen en la cultura ibérica. Hay, primero, una intención documental, un deseo de reunir el mayor volumen posible de imágenes y de datos que muestren la globalidad de aspectos y manifestaciones de esta cultura. Frente a los límites habituales del libro, el formato de un Cd-Rom permite la tesaurización y acumulación de documentos. Desde este punto de vista, se ha realizado un riquísimo thesaurus con más de 1500 imágenes de la Protohistoria ibérica. El texto asimismo permite un caudal acumulativo: su estructura acepta digresiones e integra diferentes niveles de lectura, al no exigir la linealidad estricta de un libro. La inmensa bibliografía resultante - que el usuario puede consultar en un icono independiente, desde la barra del menú principal- es un indicio más de esta tesaurización.

Sin embargo, el corpus no puede ser exhaustivo pues hubiera excedido los límites de nuestro esfuerzo. Sí es sobradamente comprehensivo y muy amplio. Ni pretende ni puede recoger -está claro- todos los exvotos o las esculturas, animales, monstruosas o humanas, en piedra; o la variabilidad inagotable de las imágenes cerámicas. No tendría sentido desde nuestro planteamiento: el bosque se convertiría en una selva. Pero, claramente sin ser un catálogo o un corpus tipológico, el Cd-rom asume las principales series, tipos y variantes del repertorio ibérico con el fin de presentar los aspectos estructurales y sociales que configuran su imaginario. Similarmente, la descripción del documento no puede ser exhaustiva sino selectiva: se guía, principalmente, por la interpretación iconológica. No pretende sustituir a los catálogos tradicionales sino abrir campos de luz en la lectura de la imagen ibérica y en su universo de relaciones y contactos.

Hemos rechazado, pues, la acumulación por sí misma - hasta donde nos hubiera permitido la capacidad de un disco compacto- para no caer en un aluvión indiscriminado o incómodo de datos. Con todo, la documentación reunida es inmensa. En ella, los hilos que van guiando la amplísima selección que ofrecemos en este trabajo son, sobre todo, el análisis iconográfico y el propio discurso de las preguntas y de las propuestas interpretativas. En un laberinto de esta especie somos conscientes de que siempre faltarán aspectos olvidados o apenas insinuados. Pero el formato del Cd-Rom permite una ampliación y una revisión no excesivamente complicada y costosa en el plazo prudencial de unos años. Esta flexibilidad - junto a la enorme capacidad in- 
formativa - es una de las principales virtudes del nuevo medio que permite encauzar nuestro estudio y ordenación de la imagen.

El análisis aquí desarrollado de la imagen entiende la cultura ibérica de una manera original atendiendo a sus propias características, pero situándola en el amplio marco de las culturas mediterráneas de la antigüedad. La imagen no se entiende en sí misma, sino dentro del proceso histórico y social que la arropa. Una imagen aislada apenas dice nada por sí sola, sin el juego de relaciones que van construyendo sus significados. La relación de la imagen dentro de su propio sistema y contexto - espacial e histórico- y las connotaciones de este sistema con las otras culturas coetáneas, principalmente las del mundo Mediterráneo, son las claves que van iluminando los diferentes usos y significados iconológicos. Sobre estas bases se formulan las hipótesis y las conjeturas.

La génesis del proyecto parte de una exposición itinerante, La sociedad ibérica a través de la imagen, que desde 1992 circuló por museos y casas de cultura de España y de Europa (Olmos, 1992). Sienta, por tanto, sus cimientos sobre una experiencia al tiempo científica y museológica. El discurso iconográfico que constituye el núcleo o el punto de partida quedó establecido en el proceso de dicha exposición. Se resumía en torno a unas pocas preguntas-clave que trataban de situarnos en el punto de vista del espectador medio de nuestra sociedad, para introducirse enseguida en un método de lectura y atisbar luego las diversas formas de autorepresentación de una sociedad antigua como la ibérica. Estas son las cuestiones latentes bajo la trama: cómo podemos interpretar imágenes como las ibéricas, alejadas de nosotros en más de dos mil años y pertenecientes a esa tierra extraña del pasado; cómo se construye esa imagen, es decir, cuáles son los signos y sus combinaciones, las normas compositivas, sus códigos; y, por último, cuál es el contexto de la imagen y la relación y diálogo que la sociedad ibérica establece a través de su iconografía: es decir, sus principales usos y sentidos. La muestra planteaba, de manera sencilla, estas y otras cuestiones en la secuencia narrativa de un centenar de paneles. Cada panel constaba de un texto breve, acompañado de cuatro o cinco imágenes y de un mapa de localización de los yacimientos a los que aquéllas se referían. De este modo, el panel constituía un pequeño núcleo temático, que ha servido hoy como célula en el organismo iconográfico del Cd-rom. El antiguo discurso se adapta bien al nuevo soporte. La experiencia de la exposición nos sirvió para atisbar la validez y el alcance de este guión en relación con el público, amplio y diverso, que la visitó a lo largo de aquellos tres o cuatro años (1992-1995) ${ }^{7}$. Creemos que las preguntas de entonces siguen siendo interesantes y fecundas hoy día.

Sobre este núcleo se elaboró una propuesta nueva (cuadro 1). Era necesaria una introducción general al mundo ibérico, que se encargó a especialistas de este ámbito. No se podía partir de la imagen sin hablar antes de los iberos y exponer qué es lo que los investigadores de nuestra generación opinaban del tema. A este primer gran bloque seguiría el núcleo central (Las imágenes de los iberos), que da paso al catálogo o repertorio de imágenes. Dentro de esta parte se presentan los distintos índices, que seguidamente veremos.

\section{Nivel I - Introducción al mundo ibérico}

Textos de: Arturo Ruiz (Universidad de Jaén), Teresa Chapa (Universidad Complutense de Madrid), M. Paz García-Bellido (IH, CSIC, Madrid) y María Belén (Universidad de Sevilla).

1 - Las ciudades ibéricas y su territorio.

2 - La economía. - Iconografía de la moneda hispánica.

3 - El Comercio.

4 - La religión ibérica.

- El santuario de Carmona (Sevilla).

5 - La muerte y el mundo funerario.

$$
\text { Nivel II - Las imágenes de los iberos }
$$

Textos de: Ricardo Olmos (IH, CSIC, Madrid) con la colaboración de Isabel Izquierdo (IH, CSIC, Madrid),

Francisco Martínez Quirce (Madrid) y Trinidad Tortosa (IH, CSIC, Madrid).

1 - Un recorrido por la imagen ibérica.

- Aproximaciones a unas imágenes desconocidas.

- La interpretación de las imágenes importadas.

- La búsqueda de un lenguaje propio.

- La creación de una narrativa.

- La imagen romanizada.

- Imágenes celtibéricas.

2 - Repertorio iconográfico (Catálogo).

Cuadro 1.-Estructuración general del Cd-Rom Los iberos y sus imágenes.

\subsection{Introducción al mundo ibérico}

Esta parte presenta sucintamente el marco histórico de esta cultura a través de los parámetros de

7 No se llevó a cabo, sin embargo, una valoración sistemática de la exposición mediante tests de comprensión de contenidos y lenguajes por parte del público. Sí hubo una valoración indirecta del contenido de los paneles a través de un vídeo a un público universitario, realizado en marzo de 1994 en un curso sobre imagen ibérica dirigido a postgraduados. Desarrolló el diseño y la valoración del test la doctora Ángela García Blanco, del Museo Arqueológico Nacional. Los resultados del test permanecen inéditos. 
espacio, tiempo y procesos sociales. Consta de cinco apartados: poblamiento y territorio; economía; comercio; religión; mundo funerario. Dentro del epígrafe «Economía» se ha incluido un texto monográfico sobre la moneda ibérica y su iconografía. Dentro del epígrafe «Religión» se ha incorporado otro breve texto sobre el santuario orientalizante de Carmona (Sevilla), donde el contexto ilumina un conjunto iconográfico de raíz fenicia de gran relevancia.

Esta introducción, aunque es muy breve y sencilla, tiene una finalidad doble: contextualizar o arropar el campo iconográfico que se estudia detenidamente en la segunda parte; apuntarle al lector las principales pautas de la investigación actual sobre los iberos.

\subsection{Las imágenes de los iberos}

Se trata del núcleo fundamental de este CdRom. Dentro de este nivel hay dos opciones: la primera ofrece un recorrido por la imagen que introduce de una manera global al lector en sus múltiples significados (se sigue, en una gran medida el recorrido lineal de una exposición). Ello permite la posibilidad de seguir un hilo narrativo, secuencial. Pero también se puede acceder a cada uno de sus subapartados temáticos de un modo totalmente independiente, de acuerdo con las preferencias o prioridades del usuario.

El cuadro 2 refleja la estructura general de este bloque, que inmediatamente explicaremos.

1. Aproximaciones a unas imágenes desconocidas. - ¿Cómo acercarnos al universo figurativo ibérico?

- Las primeras interpretaciones.

2. La interpretación de las imágenes importadas.

- Imagen griega, interpretación ibérica.

- Originales mediterráneos e imitaciones ibéricas.

- Imágenes mediterráneas en monedas.

3. La búsqueda de un lenguaje propio.

4. La creación de una narrativa.

- El lenguaje ambiguo de la imagen

- El lenguaje del espacio.

- La imagen ¿espejo de la sociedad?

5. La imagen romanizada.

6. Imágenes celtibéricas.

Cuadro 2.-Estructuración general del capítulo Un recorrido por la imagen ibérica.

Este guión combina principalmente tres criterios: el historiográfico, el cronológico y el tipológico. La aproximación historiográfica parte de la pregunta clave y genérica de cómo acercarnos e interpretar unas imágenes de las que apenas tene- mos otras referencias que las que ellas mismas nos ofrecen. Tras las preguntas generales a modo de introducción o prólogo, «¿cómo acercarnos al universo figurativo ibérico?» y «¿qué significan sus imágenes?», se expone una breve historia de la interpretación desde el siglo XVI (disquisiciones numismáticas) hasta nuestros días. Se incluyen, además, interpretaciones tan diversas como las aproximaciones románticas, etnográficas - con un guiño a las lecturas casticistas y populares - así como manipulaciones políticas y nacionalistas, entre otras. Dibujo, fotografía y descripción son analizados desde esta perspectiva historiográfica pues forman parte del proceso interpretativo. La dialéctica entre la referencia de los textos antiguos de los autores grecolatinos y la imagen ibérica - con sus posibilidades asociativas y sus caminos tantas veces divergentes- es un aspecto importante que está también presente en este apartado y en todo el $\mathrm{Cd}$.

En los apartados siguientes se analiza ya la imagen ibérica desde una óptica en parte histórica y, en parte, estructural. Se combina el criterio diacrónico con el sincrónico. La lectura diacrónica considera la génesis de la imagen ibérica en la multiplicidad y complejidad de la historia mediterránea, partiendo de los precedentes más inmediatos (apartado II) -alusiones al Bronce final, un desarrollo mayor en la época orientalizante y tartesia...-, incluyendo las importaciones del comercio mediterráneo y las imágenes de las llamadas «colonizaciones» y su apropiación local, etc. Los apartados III y IV se centran, siguiendo este hilo cronológico, en la propia cultura ibérica. Y se concluye con la romanización (apartado V). Como contrapunto, y a fin de proporcionar una visión más amplia de la iconografía prerromana en la Península ibérica, se dedica un apartado final —breve y altamente selectivo- a las imágenes celtibéricas (apartado VI).

A este esquema que aceptamos como genéricamente evolutivo (precedentes; desarrollo; interrelaciones y consecuentes) se superpone un criterio tipológico-temático (apartados III y IV). En una exposición ahora ya sincrónica, se agrupan las imágenes, de manera jerarquizada — de lo más simple a lo complejo- y siguiendo categorías en gran medida tipológicas: signos geométricos; imágenes animales, vegetales...; imagen humana... Ésta última se dispone, a su vez, por tipos y por escenas. A modo de ejemplos: hay un capítulo dedicado a los «elementos florales»; otro a las «esfinges»; otro a los «lobos»; otro a. las «damas sedentes»; otros a las «escenas de caza», de «sacrificio» o de «guerra», etc.

A primera vista puede parecer que con estas ca- 
tegorías tipológicas imponemos a la realidad un corsé rígido y evolutivo basado en los criterios de «la taxonomía» y de «la cadena del ser». En la realidad no es así: tanto una lectura continua y detenida de los textos como las interrelaciones continuas a que nos abre el Cd-Rom nos asoman a una imagen ibérica versátil, mudable y fluida. Nuestro propio discurso trasciende continuamente los límites clasificatorios e, inevitablemente, los signos cruzan las fronteras taxonómicas y se combinan. El lector o usuario comprobará enseguida estas afirmaciones. Por un lado, él mismo podrá seguir el serpenteo de un mismo icono en los más diversos campos temáticos: a este camino de las interrelaciones volveremos más adelante, cuando hablemos del catálogo propiamente dicho.

Pero, sobre todo, los mismos signos son mudables. Por ejemplo, los elementos geométricos —que parecen ocupar su lugar preciso en nuestro tanteo clasificatorio- se comportan o funcionan muchas veces como símbolos vegetales, cuando con ellos se construye una imagen: una secuencia o combinación de triángulos rayados o de círculos es una fórmula de la que puede servirse un ceramista, para resaltar la tectónica y enmarcar el campo figurativo de un vaso; para emular sobre un vaso los «gallones» de un modelo metálico; para representar el icono «flor». A su vez, los elementos florales a veces se utilizan para construir paisajes (el movimiento y fecundidad del mar se representan con roleos y flores). Y, con cierta frecuencia, aquéllos se integran y transforman en ornamentaciones animales y monstruosas, trascendiendo sus significados de acuerdo con los contextos. Un motivo floral puede configurar incluso el esquema mítico de una barca solar, como vemos en una cerámica de Azaila (Teruel). La naturaleza ibérica — si es lícito utilizar este nombre abstracto- se muestra engendradora y metamórfica. A estas mutaciones atiende nuestro discurso de las imágenes.

Es bien sabido que también el ámbito animal ibérico oscila entre el reino de lo fabuloso y de los monstruos, por un lado, y, por otro, el reino domesticado de lo humano. Un lobo puede funcionar, al modo de un león o de un grifo, como signo de oponente monstruoso en un enfrentamiento heroico (la lucha iniciática del héroe frente al león de época orientalizante a veces se transforma en un certamen del joven con un lobo); otras veces el lobo se muestra como ser devorador: a través de sus entrañas se realiza un tránsito al allende. Se subraya ahora su carácter de ser mediador y liminal, de los infiernos. En otras ocasiones - por ejemplo, en la cerámica de Elche- el signo del «lobo» funciona en imágenes de génesis y surgimiento, dentro de una representación de la naturaleza que suponemos cosmogónica ${ }^{8}$. Otras veces aparece como signo o epísema aristocrático, decorando la coraza o kardiophylax del guerrero de La Alcudia de Elche. Podríamos prolongar estos ejemplos. La voz -o el icono «lobo»- adquiere significados y funciones diferentes; el ibero metaforiza una y otra vez sus sentidos. La sociedad ibérica otorga significados diferentes a signos formalmente similares. Éstos son abiertos, receptores y creadores de significaciones. Y, situados fuera de contexto, obligadamente ambiguos. En consecuencia, las tipologías rígidas se disuelven en los ejemplos y cualquier criterio clasificatorio inicial se modifica y enriquece contextualmente.

Pero, además, los signos pueden mantener (por conservadurismo o prestigio) su significado básico originario; o, al contrario, cambiar sus usos y funciones en el proceso social del tiempo. La dama ibérica, sentada o de pie, puede ser un signo eficaz en un santuario como el del Cerro de los Santos a lo largo de muchas generaciones: los oferentes repiten, por prestigio, gestos del pasado, que el artesano en todo caso esclerotiza formalmente. Por el contrario, un exvoto ibérico asume un gesto de libación nuevo, más propio de la iconografía itálica, en los ejemplos tardíos de la acrópolis de Sagunto: se apunta en ellos una innovación clara frente a los tipos de la tradición ibérica. Y hay sobre todo imágenes en que ambas tendencias coexisten para asumir significaciones diferentes: mantienen un rasgo tradicional, incluso un arcaísmo, junto con marcadas innovaciones. La pátera de Santisteban del Puerto (Jaén) combina la vieja concepción ibérica del lobo como animal devorador y de tránsito con la iconografía, ahora importada de la Italia republicana, del cortejo dionisíaco de érotes y centauros. Las mutaciones revisten una profunda significación histórica.

Nuestro discurso del Cd-Rom trata de incorporar todas estos cambios de sentido que explican la versatilidad y riqueza de la imagen ibérica de acuerdo con los contextos y con la historia. La estructura tipológica no deja de ser, pues, un armazón artificial pero útil en el que acoplar la versatilidad y rebeldía de los datos dentro del camino laberíntico, con vueltas y revueltas, del discurso iconográfico.

Hasta aquí hemos hablado de las posibilidades y dificultades de ordenar los materiales en un texto serpeante y de cómo las mismas imágenes, a través de su pluralidad de significados, nos remiten a ámbitos temáticos diversos. Está claro que un mismo documento puede integrarse, desde perspectivas di-

\footnotetext{
8 R. Olmos, 1990.
} 
ferentes, en discursos distintos. De este modo, la dama de Elche puede figurar en el primer apartado historiográfico — cómo se ha descrito, cómo se ha dibujado o fotografiado; qué connotaciones nacionalistas asume y que reacciones casticistas ha suscitado; cómo ha servido su icono para construir las raíces de una historia nacional o el propio discurso sobre el arte ibérico-. Pero también esta misma imagen puede integrarse bajo el caparazón más tipológico: los bustos como monumentos funerarios, comparando a la Dama con los ejemplos de Guardamar de Segura (Alicante) o el más tardío busto del varón de Baza (Granada) con un similar orificio posterior. También la dama de Elche puede leerse desde una secuencia sobre el género: indumentaria, tocado, adornos...; la concepción ibérica de las damas, la expresión sagrada de lo femenino ibérico, etc.

Asimismo, las escenas del complejo plato de Tivissa (Tarragona) se encuadran globalmente en los ensayos de un programa narrativo sobre una iniciación funeraria. Pero también sus diversas escenas se descomponen y analizan para integrarse, respectivamente, en el contexto de la caza y la lucha animal, o en el sacrificio. El mismo lobo del medallón reclama su voz propia. Pueden multiplicarse los ejemplos. Se anticipan con ello las riquísimas posibilidades de relaciones (por medio de hiperenlaces) que veremos a continuación en el catálogo.

\subsection{El Catálogo de imágenes}

El catálogo, que se presenta simultáneamente junto con este segundo nivel en la misma pantalla del libro electrónico, se ha concebido como un fondo documental o thesaurus, altamente especializado. Los registros del catálogo no se limitan a piezas, sino que recogen documentos de tipo diverso. De este modo, hay registros que constituyen verdaderos artículos o ensayos sobre temas iconográficos amplios -y no específicamente sobre piezas concretas, como aquellos que reflexionan sobre la interpretación de la imagen ibérica desde el dibujo, la fotografía y la descripción; o la que refiere la historia de los estudios de iconografía de los iberos a través de sus principales protagonistas. Existen, por ejemplo, epígrafes bio-bibliográficos dedicados a investigadores y eruditos que se han ocupado originalmente de imagen ibérica como es el caso de la figura de Antonio García y Bellido. Un registro analiza la clasificación iconográfica del Corpus Vasorum Hispanorum de Liria, etc. Hay un campo dedicado al tema de la falsificación y a la disyuntiva falso/verdadero, que apunta a la fragilidad del cono- cimiento, a la manipulación de la historia y, en definitiva, a nuestro proceso de construcción interpretativa. Pero, por lo general, los registros equivalen a objetos o imágenes individuales o incluso a aspectos parciales de dichas imágenes, como en el citado ejemplo de la pátera de Tivissa, a la que podemos acudir en el catálogo tanto desde su lectura global y unitaria como de forma parcial, siguiendo su descomposición en las sucesivas escenas del friso. En este caso diferentes números de catálogo envían al mismo objeto desde análisis y ópticas diferentes ${ }^{9}$.

El contenido de los registros se anuncia en los títulos. Los títulos incluyen a veces las clásicas denominaciones que aparecen en la literatura especializada y que han sido asumidos por la investigación. De este modo se mantienen algunas de las denominaciones o apelativos originales con lo que aún conocemos los vasos de San Miguel de Liria (Valencia): «vaso de los guerreros», «vaso de la sardana», «vaso de la danza guerrera» ${ }^{10}$. Pero, generalmente, empleamos denominaciones más asépticas, que, en lo posible, aglutinan un contenido diferencial y descriptivo: «Exvoto de mujer desnuda, sonriendo y mostrándose, del santuario de Castellar de Santisteban (Jaén)» o «Caja o urna cineraria con ciervas y árbol de Toya (Jaén)». Ello permite, en gran medida, anticipar la pieza al lector que acude al índice, distinguiéndola así de otros exvotos o de otras urnas. Esta descripción contiene asimismo elementos descriptivos de tipo iconográfico que constituyen el núcleo del índice analítico, al que enseguida nos referiremos.

Cada registro incluye inicialmente una ficha-tipo con los datos básicos de los documentos: definición, soporte material, localización geográfica, contexto arqueológico, dimensiones generales, lugar de conservación, cronología propuesta - muchas veces obligadamente imprecisa e insegura-, y bibliografía, así como las posibles comparaciones y asociaciones que surgen de todo documento arqueológico. A la ficha sigue una lectura iconográfica: el análisis, la descripción y la interpretación se funden en una secuencia única e inseparable (no mantenemos

${ }^{9}$ En el catálogo esta remisión a diferentes análisis del objeto se realiza a través de la abreviatura «cf.» seguido del número de registro correspondiente.

${ }^{10}$ La mayoría de estas denominaciones forman parte asimismo del discurso historiográfico y deben ser asumidas críticamente, como características de una época y de un modo de pensar la imagen y la arqueología: algunas revisten un peculiar carácter casticista o continuista de la historia («vaso de la sardana») o peligrosamente trivializador («vaso de la Pepona», referido al conocido recipiente de La Alcudia de Elche con el rostro frontal), que aúna nuestra perplejidad y condescendencia modernizante ante la seriedad y solemnidad de la imagen. 
la vieja e inútil división entre descripción e interpretación, que tanta rémora ha supuesto para la explicación y comprensión iconológicas). El texto insiste en la capacidad connotativa de la imagen, es decir, en la riqueza de sus significados y en su posibilidad de asociaciones. En esta descripción, amplia, pueden aparecer disgresiones y comparaciones relacionadas de modo muy diverso con la pieza, de carácter formal o conceptual, tanto con otros ejemplos del mundo ibérico, como incluso, con paralelos (basados en la analogía o en el contraste) de otras culturas del Mediterráneo antiguo. Cada documento crea en torno a sí mismo una constelación de relaciones que mutuamente se configuran y sustentan. Se crea, por tanto, un discurso o una trama densa y serpenteante en la cual el documento iconográfico nos ofrece una multiplicidad de relaciones y de significados. De esta descripción-interpretación surge la pluralidad de combinaciones con otros documentos del corpus a los que se puede acudir mediante los denominados hiperenlaces, que en el texto se resalta con un número que hace referencia al registro de la base de datos del libro electrónico. De esta manera, el usuario puede «navegar» o trazar infinitos recorridos a través de las relaciones, las analogías, las evocaciones, los contrastes... El Cd-Rom actúa así como un libro continuamente abierto e inacabado.

\subsection{Los índices}

Los índices ofrecen posibilidades diversas de acceso a la información. La elaboración de estos índices se ha basado, por un lado, en los datos de las fichas descriptivas de cada documento y, por otro, en el título que encabeza y describe sumariamente cada registro.

A través del índice general temático se puede acudir al discurso general o narrativo sobre la imagen ibérica. El índice desplegado muestra, pormenorizadamente, el listado de títulos de todos los documentos, principales y asociados, que constituyen los números del catálogo. Ya hemos indicado que estos títulos concentran el contenido descriptivo. En la información del título se incluye además la procedencia del documento: «Fragmento de terracota de mujer con huso de la necrópolis de Coimbra del Barranco Ancho de Jumilla (Murcia)». Pero hay además otras posibilidades de búsqueda. El libro electrónico ofrece para ello tres índices:

1. Índice topográfico. Incluye las referencias a los lugares de procedencia de las piezas del catálogo.
2. Índice de museos. Incluye las referencias a los museos y colecciones, nacionales e internacionales, de las piezas del catálogo.

3. Índice analítico. Incluye las palabras-clave de los temas y motivos iconográficos.

A través del índice topográfico se pueden realizar búsquedas, por ejemplo, de todos los documentos contenidos en el Cd-Rom del yacimiento de Toya (Jaén) o del Cerro de San Miguel de Liria (Valencia), etc. Similarmente, desde el índice museístico, el lector podrá acudir a todas las piezas que se mencionan conservadas en el Museo Arqueológico Nacional, en la Colección Emeterio Cuadrado de Madrid, etc.

El índice analítico recoge aquellos términos y expresiones que se encuentran en los títulos del catálogo. Por ejemplo: desde expresiones simples como «diosa» o «dama», nombres propios como «Tanit» o «Astarté», objetos como «lanza» o «falcata», gestos, actitudes y acciones como «oferente», «amamantar», etc. Se trata de un pequeño diccionario de voces sobre imagen ibérica. Es el germen, de modo muy reducido, de lo que un día podrá ser un gran diccionario de imagen y religión ibéricas, al que aludiremos en el último apartado de nuestro texto.

Del árbol general surgen además dos iconos:

Uno de ellos, en formato de libro electrónico, permite visualizar cerca de dos centenares de localizaciones topográficas -MAPAS-, citadas en el catálogo, siempre referidas a la Península ibérica.

El documento de texto llamado BIBLIOGRAFía comprende alrededor de 1.500 títulos, ordenados alfabéticamente por autor, con un acceso fácil y automático. Ofrece una referencia actualizada sobre iconografía ibérica y mediterránea.

En definitiva, hemos pretendido elaborar una obra que suponga una herramienta de trabajo para cualquier especialista en la materia y, por otro lado, un riquísimo y actualizado apoyo documental para cualquier usuario interesado en la cultura ibérica, la arqueología, la historia o las religiones y mitos del Mediterráneo antiguo. El estudio de la imagen en su contexto permite afirmar que este Cd-Rom trasciende el campo de la iconografía en su consideración tradicional. No es un mero repertorio de imágenes ni un simple catálogo de referencias. Introduce la perspectiva metodológica con propuestas nuevas de lectura de la imagen ibérica; explicita y analiza los códigos de los diferentes lenguajes iconográficos. En síntesis, nos encontramos de hecho ante una obra sobre la cultura ibérica, que vemos principalmente proyectada simbólicamente, es decir a través de la representación de su universo imaginario. 


\section{MÁS ALLÁ DEL CD-ROM}

Estamos lejos de considerar en este libro electrónico Los iberos y sus imágenes una obra cerrada y definitiva. Por un lado, queda pendiente el reto didáctico que se desmembró del proyecto originario: lograr esa ruptura con nuestro lenguaje especializado y elaborar un guión sumamente sencillo y atractivo para un público que sea, efectivamente, muy amplio; explicar nuestra visión de los iberos a la sociedad actual; ayudar a integrar esta nueva perspectiva en un paradigma moderno colectivo sobre esta pequeña parcela de la historia, con la pretensión de eficacia que lograron nuestros antecesores del siglo XIX en sus Historias de España. Esta tarea puede encontrar el cauce más tradicional de un libro -ya escrito por nosotros como guión del originario Cd Rom ${ }^{11}$ - o, de nuevo, optar por las posibilidades del formato electrónico. Simultanear ambas opciones parece lo más recomendable. Pronto se anunciarán las opciones.

Queremos ahora resaltar un segundo aspecto, el que se refiere al carácter abierto que debe tener un Cd-Rom de investigación de las características del que hoy aquí presentamos. El campo de la imagen se amplía continuamente y nuevos documentos y nuevas interpretaciones siguen transformando, día a día, nuestras perspectivas. El paradigma de lo ibérico queda aún lejos de estar cerrado. Más bien, estamos aún asistiendo al proceso mismo de su configuración. En este sentido es deseable que nuestro Cd-Rom responda a esta corriente inacabada, fluída y en continua recomposición de la investigación. Su estructura lo permite.

No deben acabar en este libro las perspectivas a largo plazo de nuestra línea de investigación. La investigación actual de la cultura ibérica está modificando muchas de las propuestas que se aceptaban hasta la fecha. El conocimiento paulatino del poblamiento y del territorio; la dinámica social, la evolución del poder aristocrático, sus complejas formas de autorrepresentación; las relaciones históricas que se establecen dentro del ámbito del Mediterráneo con la dialéctica económica y política que cada época realiza y expresa de modo diverso (interacciones con el comercio fenicio y griego, con el norte de África; las respuestas al mundo itálico y a Roma, etc.). El discurso de la historia modifica necesariamente nuestra concepción de la iconografía. Lo que se inició, años atrás, como una lectura de los códigos iconográficos de la imagen, reclama ahora cre"I. Izquierdo, V. Mayoral, R. Olmos y A. Perea, en
prensa. cientemente una aproximación integral de aquellas propuestas en la dinámica social y económica de los espacios y los tiempos ibéricos. La publicación de este Cd-Rom deberá provocar una discusión y contraste de lo que aquí decimos al entrar en diálogo con otras investigaciones paralelas. Sin ese diálogo futuro nuestra investigación habrá sido, en cierta medida, estéril.

Pero, sobre todo, el Cd-Rom nos ofrece el germen de un proceso más ambicioso y colectivo que sólo podrá llevarse a cabo con el esfuerzo amplio de muchos investigadores. Queremos anunciar la elaboración de un léxico de iconografía prerromana de la Península ibérica (Léxico LYNX) que uno de nosotros ha expuesto ya recientemente en el foro internacional de una revista científica ${ }^{12}$. Este proyecto tiene como objetivo el análisis de los diversos imaginarios que constituyen las culturas de la Penínula Ibérica a lo largo de todo el primer milenio a. C. Estimamos en, al menos, mil quinientas voces el campo semántico que debería cubrir este léxico que busca integrar las diversas facetas y ópticas de la investigación (arqueológico-históricas, lingüísticas, epigráficas, numismáticas, etnológicas, etc.) por medio de un diálogo generador de relaciones y propuestas nuevas. La base documental de este léxico sería la imagen de las culturas de la Península Ibérica. La experiencia metodológica y práctica del actual Cd-Rom sienta las bases y los criterios para el futuro proyecto del Léxico LYNX.

Varias son las posibilidades que se hayan en el germen de esta obra. La primera es la redacción de un libro que sirva de introducción a la iconografía ibérica -o prerromana, en general-, lectura que debe partir principalmente desde una reflexión del método. En esta presentación de nuestro trabajo hemos aludido, sumariamente pero con insistencia, a la corriente metodológica que permea nuestras propuestas. Estas continuas intrusiones en los aspectos del método requieren un libro introductorio que reúna y organice nuestra reflexión y síntesis sobre los aspectos, en gran medida teóricos, de un análisis de la imagen ibérica.

La segunda tarea es la integración mayor de la cultura ibérica en el Mediterráneo antiguo (un Mediterráneo en sentido amplio, no restrictivo). Sin esa discusión permanente con el mundo etrusco, itálico, púnico y norteafricano, griego, romano o céltico ..., será difícil ir mucho más allá en nuestro limitado horizonte de conocimientos y métodos. Las diferentes culturas antiguas se relacionan de manera más íntima y profunda de lo que aún logramos sospe-

\footnotetext{
12 R. Olmos, 1995/97.
} 
char. Las conexiones y los cruces son constantes. Bien evitados comparatismos y difusionismos reduccionistas, las asociaciones son iluminadoras. Sin el contraste con otros sistemas no conoceremos nuestro propio ámbito. Deberemos hacer propio el famoso dicho de Goethe sobre las lenguas: «Wer eine kennt, kennt keine» («Quien una sola conoce, no conoce ninguna»). Existen cauces internacionales para esta discusión, programas europeos que deberán promoverse colectivamente.

Y, por último, en una perspectiva temporal necesariamente amplia, aludamos aún a la realización colectiva del Léxico LYNX que aquí anunciamos. Un trabajo de este tipo no se puede realizar sin la participación de múltiples especialistas que elaboren las diferentes voces bajo la coordinación y unificación de un comité de redacción y un comité de expertos. Pero tampoco podrá llevarse a término un Léxico de esta envergadura sin una infraestructura humana que lleve a término el establecimiento y seguimiento de la base de datos informática $\mathrm{y}$, en especial, el tratamiento adecuado de todos los registros iconográficos y textuales. Ello requiere una continuidad laboral a largo plazo. Aquí radica la principal dificultad que hoy vemos para un proyecto de esta envergadura, proyecto en el que se tratan de superar los límites individuales de la investigación para transformarse en una empresa colectiva. En la organización de su gestión tal vez hayan de centrarse los principales esfuerzos de nuestra línea científica durante los próximos años.

\section{BIBLIOGRAFÍA .}

IZQuierdo, I. (1999): «La difusión de la Arqueología a través de la tecnología multimedia: El Cd-Rom Los iberos y sus imágenes». Actas del XXV CNA, Museo de Prehistoria «Domingo Fletcher»- Servicio de Investigación Prehistórica de Valencia (Valencia, 1999), 512-518.

IzQuierdo, I.; Martínez Quirce, F.; Mayoral, V. y Morillo, M. (1998), La sociedad ibérica y sus imágenes. Divulgación e investigación en informática de la cultura ibérica. Congreso Int. $L a$
Historia en una nueva frontera. XIII International Conference of the Association for History \& Computing (Toledo, 1998). Publicación: en CdROM «History in a new frontier», F. Aranda, F. Fernández y P. Sanz (Eds.), 1998. Universidad de Castilla-La Mancha.

IzQuierdo, I.; Mayoral, V.; Olmos, R. y Perea, A. (en prensa): Un viaje a la cultura ibérica, Madrid.

Martínez Quirce, F. y Mayoral, V. (1998): «Los iberos y sus imágenes. La difusión en Cd-ROM de una propuesta científica». Comunicación presentada al Congreso Internacional: Los Iberos, Príncipes de Occidente (c. 550-150 a.C.) (Barcelona, 1998).

Olmos, R. (1990), «Original elements and mediterranean stimuli in Iberian Pottery». Mediterranean Archaeology, 3, 7-25, pls.7-17.

Olmos, R. (dir.) (1992): La sociedad ibérica a través de la imagen. Catálogo de exposición (1992). Ministerio de Cultura. Madrid.

Olmos, R. (1995-1997): «Léxico de iconografía peninsular prerromana LYNX: una propuesta para la próxima década», O Arqueólogo Português, Serie IV, vol. 13/15, pp. 267-285.

Olmos, R. e Izquierdo, I. (2000a): «Los iberos y sus imágenes. Una enciclopedia de la imagen ibérica en Cd-rom». Revista de Arqueología, marzo, 227, 26-37.

Olmos, R. e Izquierdo, I. (2000b): «El Cd-rom Los iberos y sus imágenes. Un análisis de la cultura ibérica a través de la iconografía». Revista $A r$ queoweb, abril, http://teleline.terra.es/personal/ jtovar/Articulos/cd-romiberos.htm.

Olmos, R. e Izquierdo, I. (2000c): «El Cd-rom Los iberos y sus imágenes. Un análisis de la cultura ibérica a través de la iconografía». Revista $A r$ queoweb, abril, http://www.ucm.es/info/arqueoweb.

Olmos, R. e Izquierdo, I. (en prensa): «El Cd-rom Los iberos y sus imágenes. Dialéctica a tres bandas». Comunicación presentada al $3^{\circ}$ Congreso de Arqueología Peninsular (Vila Real, Utad, 2226, 1999). Universidad de UTAD, Portugal.

Perea, A. (1999): Memoria de Iberia. Ed. Polifemo. Madrid. 